\title{
"You Say Praise, I Say Encouragement" - Negotiating Positive Behavior Support in a Constructivist Preschool
}

\author{
By Victoria Carr ${ }^{*} \&$ Mary Boat $t^{*}$
}

\begin{abstract}
A participatory action research study conducted at the Arlitt Child Development Center, a laboratory preschool at the University of Cincinnati, used naturalistic inquiry to create a solution for addressing challenging behaviors within an early childhood developmental and constructivist framework. In focus groups facilitated by a school psychology doctoral student, the center's preschool teachers created constructivist strategies for addressing a Tier I Positive Behavior Intervention and Support (PBIS) framework that was based on Response to Intervention (RTI) processes. The aim was to assess the dissonance between behavioral and constructivist approaches to early childhood interventions, often most evident in teacher language used and the emphases on reinforcement strategies in behaviorist literature. Researchers employed eco-constructivism, a philosophical perspective for addressing challenging behaviors that emerge within the ecology of the classroom, to interpret teachers' responses that were oriented toward fostering children's self-regulation skills and child agency. Findings indicate that an eco-constructivist approach to PBIS may serve as a model for blended practices in early childhood programs.
\end{abstract}

Keywords: early childhood education, eco-constructivism, challenging behaviors, positive behavior and intervention supports, self-regulation.

\section{Introduction}

Early childhood educators work in varied types of preschool programs. These include Montessori, Reggio Emilia, Waldorf, nursery school or within programs that have self-identified monikers and pedagogical orientations. Yet, most early childhood programs use curricula grounded in constructivism, where children construct knowledge through their interactions with materials, adults, their peers, and their ideas (Bruner, 1966; Dewey, 1910; Piaget, 1962; Vygotsky, 1978). Stemming from the tenets of what educators in the United States of America (USA) call developmentally appropriate practice, teachers who are well-grounded in theory and constructivist practice reject behavioral teaching approaches because constructivism belies the processes of reinforcement and direct instruction. However, within the scope of a high performing classroom that is developmentally appropriate, practices range from inquiry and scaffolding to intentional instruction techniques such as prompting, modeling,

${ }^{*}$ Professor \& Executive Director, Arlitt Center for Education, Research, \& Sustainability, University of Cincinnati, USA.

${ }^{\dagger}$ Associate Professor \& Director, School of Education, College of Education, Criminal Justice, \& Human Services, University of Cincinnati, USA. 
and other evidence-based-practices (Copple \& Bredekamp, 2009). While terminology between behaviorist and constructivists continues to be hotly debated, when used properly reinforcement can clearly communicate to children who have challenging behaviors what behaviors are appropriate, increasing the chances the positive behavior will return. This is the essence of positive behavior intervention and supports (PBIS). PBIS is an effective method for addressing the function of inappropriate behaviors in early childhood classrooms. Yet, implementing PBIS practices in classrooms where constructivism philosophically grounds teacher-child interactions is challenging. PBIS may be particularly challenging when different disciplines engage practices based on differing theoretical approaches (e.g., a behaviorally-oriented school psychology approach within a constructivist laboratory preschool).

Inherent in constructivist early childhood classrooms is the belief that the messages children receive are very important to positive development. Messages that support children's conceptual understandings are critical to child growth and development and go beyond the learning that may result from reinforcement of behavior alone. PBIS, on the other hand, stems from a practical applied behavioral analysis stance to promote adaptive behaviors and reduce those behaviors that interfere with meaningful participation in classrooms and the community. It is certain that children, who have challenging behaviors, or those who are in need of mental health supports, are present in constructivist classrooms. Yet, the advocacy by traditional behavioral interventionists on the use of teacher "praise" to reinforce desirable behaviors can often be arbitrary or meaningless (Kohn, 1999). This is the primary reason for constructivist teachers' rejection of PBIS. However, within the classroom ecology, a continuum of strategies must be applied. How these strategies are used are primarily evident within the language used to communicate with and provide feedback to young children.

This paper presents the findings from a participatory action research project conducted in the Arlitt Child Development Center, a laboratory preschool at the University of Cincinnati, a research intensive university in the Midwestern state of Ohio in the United States. The preschool is inclusive of all children and many have challenging behaviors that emerge during the preschool years. As Bell, Carr, Denno, Johnson, and Phillips (2004) explain, these challenging behaviors may be related to health conditions, identified or unidentified disabilities, staggered or uneven development, social competence, mental health, trauma, abuse, child-rearing practices, or other environmental, interactional, or internal issues. In this study, constructivist master level preschool teachers and school psychology doctoral-level consultants were charged with creating a working model of principles and practices that would allow for teacher comfort in providing Tier I positive behavioral intervention and supports for children who displayed challenging behaviors within a constructivist classroom. We present this concept as an eco-constructivist approach to PBIS intervention. The outcomes of this collaboration produced a Tier 1 Child Support Framework for the Arlitt Child Development Center with regard to the following PBIS infrastructure: a) forming relationships, b) guidelines of the classroom, c) 
classroom schedule, d) classroom matrix of behavioral expectations for each classroom routine, e) transition signal, f) warning prior to transitions, g) preteaching, h) specific verbal encouragement, i) ratio of positive statements vs. redirections or planned ignoring, and $\mathrm{j}$ ) acknowledgement system. Overall, the collaboration resulted in a viable and acceptable model for implementing PBIS in the inclusive Arlitt Child Development Center preschool.

Given that preschool is also the first schooling experience for many enrolled children, it is often the environment in which a child may be first identified as having special needs. This is accomplished through a systematic collection of data analyzing a child's response to the curriculum, instruction, and intervention. Therefore, it is critical that teachers use evidence-based strategies within a developmental model of instruction to ensure a high quality preschool experience for children. At the Arlitt Child Development Center, the developmental model is grounded in constructivism, so intervention strategies must be acceptable to teachers who embrace this theoretical approach to teaching young children. The challenge is that PBIS is oriented to behavioral interventions that conflict with constructivist approaches to teaching.

\section{Literature Review}

Over the past 50 years, the mission of early childhood education (ECE) in the United States of America (USA) has shifted from a primary focus on developmental principles in support of typical child development serving some children to a stronger focus on serving all young children in ECE environments (e.g., preschool, group child care). This shift has focused not only on serving children at risk due to economic status (e.g., Head Start), but also the inclusion of children with special needs. The movement toward inclusion of all emanated from both legal and ethical arguments. Legal precedent supporting the rights of children with disabilities to Free, Appropriate Public Education (FAPE) in the Least Restrictive Environment (LRE) (e.g., PL 94-142; PL 99-457; PL 101476; PL 105-17; PL 108-446) provided a clear basis for seeking equity in environment and experience for young children. Moral/ethical arguments were derived from the inequities in experience and the limitations in growth for all children inherent in separate learning environments.

With the increased emphasis on providing ECE opportunities for all children in shared learning environments, the demands on teachers to understand and meet the needs of all children (e.g., children with and without disabilities) has brought together the fields of Early Childhood Education (ECE) and Early Childhood Special Education (ECSE). Although both fields share common goals, they evolved from fundamentally different theoretical models/ philosophies. Early childhood education drew significantly from theories and principles of child development, relying heavily on constructivist theories and approaches to teaching and learning (Bruner, 1966; Dewey, 1910; Piaget \& Inhelder, 1962; Vygotsky, 1978). Alternatively, ECSE evolved primarily from the behavioral principles informing special education practices (Skinner, 1953; Grisham- 
Brown, Hemmeter, \& Pretti-Frontczak, 2005). As such, the two fields grew along parallel, but fundamentally different paths. With increasing recognition of the importance of inclusive learning environments, the fields ECE and ECSE have had to consider ways to join policy and practice to promote positive outcomes for all children (e.g., Developmentally Appropriate Practices, NAEYC; DEC Recommended Practices, DEC). The resulting practices often are referred to as blended practices. At the core of blended practices in inclusive ECE environments is the belief that strategies that support children with special needs are equally beneficial to children considered typically developing (Grisham-Brown, Hemmeter, \& Pretti-Frontczak, 2005). A similar approach is supported by principles of Universal Design for Learning (UDL) providing a framework to enhance teaching and learning in ways that are more responsive to individual learning needs (CAST, n.d.). Meyer, Rose and Gordon (2014) drew from research in education, neuroscience, and technology to develop the UDL framework. The premise of the framework is to structure curriculum and instruction so that children have multiple ways to engage with the materials and activities and show they have learned the content in varying ways. Just as young children use a variety of approaches to engage their environments, they also need differing degrees of structure and direction for effective skill development (Dinnebeil, Boat, \& Bae, 2013). Within UDL, teachers use a variety of alternatives to ensure children are supported in their learning. In a preschool environment, this is often viewed as a self-leveling curriculum where materials and instructional activities can be accessed by children across developmental and multi-age groupings.

While the importance of creating blended learning environments for all children in ECE has received support, the process of blending practices has been more challenging. One major barrier to a unified set of practices has been the different terminology used in constructivist vs. behavioral approaches to teaching and learning. While the two philosophical approaches focus on different views of child agency, in many ways the actual practices encouraged by constructivism and behaviorism are similar; sometimes the difference is merely semantics. To address the discrepancy between viewpoints, Carr and Boat (2007) suggest inclusive programs adopt an eco-constructivist philosophical view for educating young children and providing intervention supports as needed. Specifically, eco-constructivism reflects an integrated view of teaching and learning using a continuum of strategies to foster ecologically sound and high quality early childhood environments that support child agency. In an ecoconstructivist environment, teacher initiated strategies support child selfregulation. In addition, eco-constructivism supports learning opportunities in which children construct knowledge through inquiry with teacher-scaffolded supports (Carr \& Boat, 2007). Behavioral supports are only used when necessary. This continuum begins with well-designed play and learning environments and instructional strategies that support child-centered learning. On the other end of the continuum lies teacher-directed instruction that utilize more extrinsic controls. While this approach blends behavioral strategies into typical programming, in eco-constructivism it does so in a way that is acceptable to 
teachers who use constructivist teaching methods. It is also an approach that explicitly values child agency and emphasizes self-regulation as an intrinsically motivated activity (Kohn, 1999).

Bronson (2000) synthesizes the underpinnings of self-regulation from psychoanalytic, behavioral, social learning, social cognition, Vygotskian, Piagetian, Neo-Piagetian, and information processing theories. Yet, it is the dramatic difference between the behaviorist's assertion that self-regulation is learned through reinforcement and the constructivist's assertion that selfregulation emerges from the need for equilibrium and problem-solving. Within an eco-constructivist approach, it is important to understand these theoretical influences on self-regulation and, in particular, the role of the teacher in supporting children's development of self-regulation and appropriate classroom behavior. An eco-constructivist approach acknowledges the influences of social learning theory on self-regulation in the context of the child's perception of the environment and his or her own effectiveness within the ecology of the environment. On the other hand, it dismisses the systematic reinforcement schedules of behaviorism, but focuses instead on the child's increasing understanding of the environment and the interactions of the people within it, or the ecology within the classroom. Thus, in an effort to address challenging behaviors in an eco-constructivist classroom, teachers focus on a continuum of guidance strategies that assist children in problem-solving by pointing out relevant features of the problem or suggesting problem-solving possibilities while modeling desirable behaviors and pointing out what children are doing to be successful in the classroom. These strategies help children develop cognitive self-regulation, independent problem-solving skills, and internalize skills for future use (Bronson, 2000).

\section{Challenging Behaviors}

ECE teachers often cite challenging behaviors as a barrier to successful inclusive environments. Statistics suggest approximately one-third of preschool age children in the US demonstrate challenging behaviors (Rescorla et al., 2011), yet teachers often feel ill-equipped to address behavioral issues. As teachers struggle to support young children with challenging behaviors, the children are at much higher risk for exclusion or expulsion from ECE classrooms (Gilliam, 2004). Therefore, in an effort to maintain an inclusive classroom, teachers may seek help and strategies from behavioral specialists, colleagues, or other resources; or they may face the challenges alone.

The demands of challenging behaviors in the classroom have clear implications for teacher professional development focused on utilization of a continuum of strategies that promote child success. To maintain the integrity of a quality ECE environment, such a continuum must be grounded in constructivist approaches supported by strategies of increasing intensity and directedness based on individual student need. Well-researched strategies such as instructional and caring contacts, or prompting, modeling, etc., contribute to children's learning and are inherent in a master teacher's pedagogical repertoire (Boat \& 
Carr, 2007). However, it has been found that preschool teachers who struggle with implementation of positive guidance strategies use fewer effective instructional strategies (Boat, et al., 2009). This lack of teacher effectiveness has strong implications for children's learning and may contribute to children being identified as having behavioral challenges and special needs when the issue is actually negative guidance and relevant pedagogy.

\section{Response to Intervention}

Response to Intervention (RTI) is a tiered model of supports for, "the early identification and support of students with learning and behavior needs" (RTI Action Network, n.d., para.1). RTI in ECE has four primary components: "...multi-tiered systems of teaching and caregiving practices; a high-quality curriculum; ongoing assessment and continuous progress monitoring; and collaborative problem solving among team members" (DEC, 2013, p. 6). These components inform process and procedure to ensure interventions move from less individualized and intensive to more individualized and intensive strategies (DEC, 2013). Using the RTI framework, challenging behaviors may be addressed at any one or across all three levels. For teachers in ECE classrooms it is particularly important that they develop proficiency with strategies within Tiers I and II (see Table 1). Positive behavioral intervention and supports can play a critical role creating classroom environments that provide children with sufficient guidance toward successful engagement.

Figure 1. Tiered Model of Positive Behavioral Intervention and Support within RTI

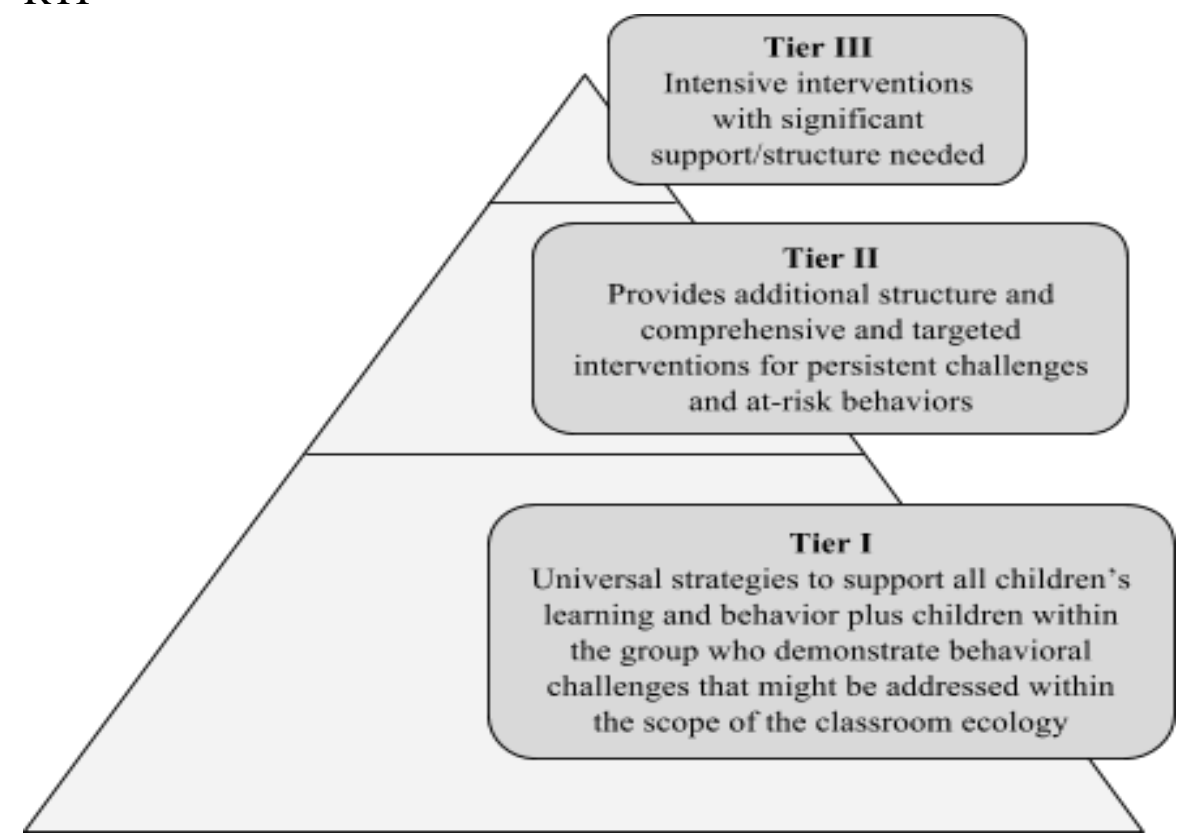

As Figure 1 indicates, within the RTI model, type and intensity of intervention is based on student response to individual intervention. Intensity of 
instructional strategies or intervention increases only when students are not responsive to less intensive approaches.

\section{Role of Positive Behavioral Interventions and Supports}

Positive Behavior Interventions and Supports (PBIS) are a well-established, evidence-based group of strategies promoting positive social skill development to decrease challenging behaviors (Fox, Dunlap \& Powell, 2002; Jolstead, Caldrella, Hansen, Korth, Williams, \& Kamps, 2016). Benedict, Horner, \& Squires (2007) assert that the essential aspects for PBIS that revolve around the universal practices include classroom materials (posted rules, schedules), transitions (warnings, signals, precorrection), and classroom routines (acknowledgement of rules, ratio of positive to negative statements, and praise). The foundations and features of PBIS are behavioral science, practical interventions, lifestyle outcomes, and a systems perspective (Sugai et al., 2000). The theoretical underpinning of behaviorism is that behavior can be predicted and controlled. Therefore, the fundamental belief of PBIS is that behavior is learned and can be changed, that teaching is a change tool, that behavior change must be socially significant, and that procedures must be socially, culturally, and contextually appropriate (Sugai et al., 2000). A continuum of behavioral supports has been advocated for within the scope of PBIS, but with the focus on evidenced-based practices prevalent in the special education behaviorist literature, such strategies are often deemed too externally driven by constructivist teachers who emphasize self-regulation and respect for child agency.

Constructivist theory is grounded in the premise that we make or construct meaning from our experiences and that the child is an active participant in his or her own learning, so constructivist teachers often reject behavioral strategies. Self-regulation, however, is a complex process and takes time with repeated learning opportunities for a child to inhibit one's actions and follow rules and procedures (Bodrova \& Leong, 2007; Blair, 2009; Bronson, 2000). Teachers must be intentional in how they support this process. This is where the PBIS and constructivist approaches intersect. When the Arlitt Child Development constructivist preschool teachers needed to address challenging behaviors in approximately $15 \%$ of its program's enrollees, PBIS strategies were introduced by a school psychology doctoral student and revised by classroom teachers. This approach to consultation has treatment integrity in intervention design through a discussion of intervention implications and the practical use of scripts (Barnett, Bell, \& Carey, 1999). School psychology students study intervention from a behavioral perspective and preschool teachers approach early childhood education from constructivist theory. Thus, scripts created through collaborative consultation can serve as a transformative process for all participants. 


\section{Methods}

The methodology for this study was a naturalistic inquiry focused on creating a solution (O'Leary, 2005) for addressing challenging behaviors within an early childhood developmental and constructivist framework utilizing the evidence-based practices inherent in the early childhood special education literature. The problem was the dissonance between the philosophical approaches to education-constructivism and behaviorism. Besides the philosophical orientation toward how children learn, teachers perceived differences in the use of language between a behaviorist and constructivist as an overt and wellversed debate of praise versus encouragement or the general praise of positive behavior using words like "good job" or an enthusiastic non-verbal reinforcer such as a 'high five' instead of authentic encouragement of child processes and agency. Positive behavior intervention and support (PBIS) is by definition a behaviorally-based systems approach to make problem behaviors less desirable for children and positive behavior more desired by children (Sugai, et al., 2000). The solution-based approach to creating an understanding of evidencebased tiered supports for addressing challenging behaviors and a framework for a positive behavior support model was a participatory action research design (Stringer, 2014). Within this approach, the researchers facilitated teacher focus groups to assess needs, envision a framework for positive behavior support, and design procedures, actions, and scripts that would guide an eco-constructivist approach to Tier I interventions in early childhood education. The aim was to provide teachers with an opportunity to clarify their positions on and strategies for using PBIS in a social context.

\section{Arlitt Child Development Center}

The Arlitt Child Development Center at the University of Cincinnati is a constructivist laboratory preschool that resides within the School of Education's Arlitt Center for Education, Research, \& Sustainability in the College of Education, Criminal Justice, and Human Services. The center is rated at the highest level for early childhood programs in Ohio and is accredited by the National Association for the Education of Young Children. With its inception in 1925, it is one of the oldest laboratory preschools in the USA. The Arlitt Child Development Center serves 136 children in 8 classrooms. The preschool program is fully inclusive of children with disabilities and is economically, ethnically and racially diverse. The fully inclusive classes of 17 children are mixed by age (3-5 years) and funding source, either tuition or Head Start, a federally-funded program for low income families. The classes are ability, socio-economically, racially, and ethnically diverse. In most years, 10- 15\% of the children have identified special needs and/or challenging behaviors. Two full day classrooms are served by three teachers each, two morning and afternoon classrooms have two teachers, respectively, who "flip", serving as lead and associate for the morning and afternoon sessions, and one morning and half day has a different lead for each session plus an assistant who teaches 
with both lead teachers.

\section{Participants}

In all, eleven teachers participated in the focus group. Six teachers held education master's degrees, two had bachelor degrees, and three had associate degrees. Of the two men and nine women teachers, all were Caucasian except two women who were Latina and African-American. At the time of this study, all teachers were employed at the preschool for 3-27 years with a mean of 14 years of service. Other participants included a school psychology doctoral student from the college's School of Human Services, who was hired by the Arlitt Child Development Center as a graduate assistant to support the Head Start mental health requirements and overall special needs within the center. She facilitated the focus group with the support of the Director of Children's Programs and the Executive Director of the research center, both of whom attempted to serve as catalysts for the generation of ideas to address challenging behaviors that impacted the ecology of the classroom. Teachers at the Arlitt Child Development Center wanted to implement effective strategies for addressing challenging behaviors, but were uncomfortable with behavioral language used as intervention common to PBIS.

Within the focus group, participants first discussed why they were studying PBIS and the significance their focus group work would have on center procedures and the children they served. They were presented with the tiered model of positive behavior support based on the PBIS literature with strategies suggested by the school psychologist doctoral student (Donovan, McCoy, Denune, Barnett, Graden, \& Carr, 2015). She requested that teachers visualize what Tier I interventions might entail for children in their care without compromising the integrity of the philosophical framework for the center. Next, the teachers were asked to brainstorm strategies and potential scripted language that might be appropriate to redirect children toward acceptable behaviors, remind children of rules and procedures, reinforce desirable behavior, encourage perseverance toward goals or skill development, and support selfregulation. The teachers' ideas were compiled into the following PBIS framework categories: a) forming relationships, b) guidelines of the classroom, c) classroom schedule, d) classroom matrix of behavioral expectations for each classroom routine, e) transition signal, f) warning prior to transitions, g) pre-teaching, h) specific verbal encouragement, i) ratio of positive statements vs. redirections or planned ignoring, and $\mathrm{j}$ ) acknowledgement system. The outcomes of the brainstorming session were compiled by the doctoral student and reviewed and edited at a subsequent teacher focus group to ensure member-checking and respondent validation (Lincoln \& Guba, 1985). 


\section{Findings}

The outcomes from the focus group were grounded in the teachers' views of authentic and constructivist teaching practices. However, consideration was given by teachers to more behavioral strategies such as using a picture exchange system for language communication. This strategy had been implemented with twin boys who had autism and were English language learners the previous year by two of the participant teachers. A discussion of discomforts related to using these behavioral strategies and the progress made by the twins with regard to communication and a reduction in inappropriate classroom behaviors supported inclusion of this strategy within the framework. This example generated additional discussion of differences in language and practices between the behavioral orientation of the school psychology program and the constructivist teachers in the preschool program. Thus, the foundations of PBIS whereby the strategies must be contextually relevant were honored by the school psychology students and, consequently, deemed acceptable by the teachers. Table 1 shows the outcomes from the focus groups with examples of acceptable language for scripted child support and intervention.

In general, within each of the categories the Arlitt teachers created language scripts with cues for positive behavior that were compatible with their philosophical approach to pedagogy. For example, "You are sitting on your mat and you are ready for group" is a statement that acknowledges the desired behavior for a child, provides positive regard, and encourages this behavior for the next transition to group. Teachers were also explicit about serving as models, designing the environment to serve as a guidance tool, and using transitions to reduce the frequency of undesirable behaviors. They proposed using visual cues in the form of picture schedules for routines and books to strengthen teacher-child-peer relationships. In addition, they were explicit about being respectful toward the child, such as stating "Use children's names rather than endearments." Overall, teachers were intentional in addressing the Tier I framework categories set forth by the school psychology doctoral student with specific script examples that would yield consistency and treatment integrity in intervention design. The language, however, was encouraging and focused on what children do to affect their own success. In addition, an emphasis was placed on child-centered problem-solving and self-regulated tasks by using inductive guidance strategies that connect behavior with its effect on oneself or others, cooperation, and choice. The use of adult and peer modeling and adult collaboration to promote prosocial behavior was also evident in the teachers' responses. 
Table 1. Arlitt Tiered Support Model with Examples

\begin{tabular}{|c|c|c|}
\hline $\begin{array}{l}\text { Tier I Child } \\
\text { Support } \\
\text { Framework }\end{array}$ & Examples & Modifications for Children who Need Additional Supports \\
\hline $\begin{array}{c}\text { Forming } \\
\text { Relationships }\end{array}$ & $\begin{array}{l}\text { - Use children's names rather than endearments } \\
\text { - Learn about and having conversations about child's personal } \\
\text { interests. } \\
\text { - Create environments to foster relationships } \\
\text { - Use positive and respectful affect } \\
\text { - Conduct home visits and have short visits at beginning of year } \\
\text { - Have respectful interactions with child's family } \\
\text { - Use active listening } \\
\text { - "All About Me Book"- each child creates a story at the } \\
\text { - beginning of the year } \\
\text { - Put things in classroom that reflect interests of children } \\
\text { another (i.e., teachers) }\end{array}$ & $\begin{array}{l}\text { - Create a transition book for classroom (specific to child including } \\
\text { interests). } \\
\text { - Conduct extra home visits. } \\
\text { - Modify transition schedule with increased parent support. } \\
\text { - Build time into schedule to form relationships (e.g., specific plan or eat } \\
\text { lunch with specific teacher). } \\
\text { - Offer appropriate choices- giving children power. }\end{array}$ \\
\hline $\begin{array}{l}\text { Guidelines of the } \\
\text { Classroom }\end{array}$ & $\begin{array}{l}\text { - State guidelines in a positive way (what you can do rather than } \\
\text { what you can't do) } \\
\text { - Use logical and natural consequences for following or not } \\
\text { following guidelines (e.g.., "If you throw sand, it may get in } \\
\text { your eyes.") } \\
\text { - Offer reason for guidelines } \\
\text { - Design classroom to be conducive to child independence, } \\
\text { making guidelines self-evident }\end{array}$ & $\begin{array}{l}\text { - Use social stories } \\
\text { - Co-create contracts with individuals or a group. } \\
\text { - Solicit parental/family input and use a consistent script with families } \\
\text { - Reduce verbal communications and use a simple direct tone/statement } \\
\text { - Use classroom zoning or child shadowing } \\
\text { - Modify the schedule or environment } \\
\text { - Individualize specific to child's needs } \\
\text { - Model and practice specific behaviors before target times of the day } \\
\text { - Make statements in a way that helps child internalize effect (e.g., "If you } \\
\text { - } \text { throw your body on the floor, you may get hurt.") } \\
\text { - Engage in positive interactions } \\
\text { non-preferred activity }\end{array}$ \\
\hline
\end{tabular}




\begin{tabular}{|c|c|c|}
\hline $\begin{array}{l}\text { Classroom } \\
\text { Schedule }\end{array}$ & $\begin{array}{l}\text { - Create a picture schedule } \\
\text { - Prepare a schedule with large blocks of time for children to } \\
\text { maintain engagement in an activity with few transitions }\end{array}$ & $\begin{array}{l}\text { - Create an interactive mobile picture schedule that may be individualized } \\
\text { for a child (e.g., a book for individual child with pictures targeted to } \\
\text { child's day) } \\
\text { - Break down difficult times of the day into smaller chunks (e.g. verbal or } \\
\text { pictorial using a choice board, or group activity) } \\
\text { - Ensure picture schedules are interactive and concrete } \\
\text { - Modify child's day to make it shorter, adding time to the day as the child } \\
\text { becomes more successful } \\
\text { - Rearrange the child's schedule if needed } \\
\text { - Respond to the needs of the children by co-planning with child(ren) or } \\
\text { sharing the lesson plan with child(ren) to get child(ren) more invested } \\
\text { (i.e. shift power to child by allowing child to make choices) } \\
\text { - Provide reminders of the schedule throughout day }\end{array}$ \\
\hline $\begin{array}{l}\text { Classroom Matrix } \\
\text { of Behavioral } \\
\text { Expectations for } \\
\text { Each Classroom } \\
\text { Routine }\end{array}$ & $\begin{array}{l}\text { - Hold teacher meetings and/or engage in conversations to review } \\
\text { expectations and make adjustments or modifications } \\
\text { - Use artifacts to specify the number of children allowed at an } \\
\text { activity (e.g., the number of smocks located at the easels or } \\
\text { sensory table) } \\
\text { - Create a written waitlist for high interest activities }\end{array}$ & $\begin{array}{l}\text { - Encourage observations of peers at targeted activity } \\
\text { - Participate with a peer (i.e., peer modeling) } \\
\text { - Begin activity with child then phase out of the play } \\
\text { - Provide explicit instructions } \\
\text { - Create and use scripts for specific responses to child's behaviors } \\
\text { - Support the child while waiting (e.g., show time on clock; discuss the } \\
\text { painting of a peer; say "what will you do when it is your turn?") } \\
\text { - Acknowledge the feelings of the child (e.g., "I know it is hard to wait.") } \\
\text { - Follow through when it is the child's turn (i.e., use the waitlist) } \\
\text { - Support other teachers when expectations/limits are stated (e.g., "I hear } \\
\text { Joe saying....") }\end{array}$ \\
\hline
\end{tabular}




\begin{tabular}{|c|c|c|}
\hline Transition Signal & $\begin{array}{l}\text { - Sing transition songs } \\
\text { - Make eye contact } \\
\text { - Give a five minute warning } \\
\text { - Allow the child to give the transition warning with the teacher } \\
\text { - Ask the child to move his or her name card dependent on the } \\
\text { activity (e.g., going to the muscle room) }\end{array}$ & $\begin{array}{l}\text { - Use a visual card - an individualized schedule } \\
\text { - Stay with the child during the transition and walk through the } \\
\text { routine. } \\
\text { - Ask the child to walk with the teacher to give the transition warning } \\
\text { to other children } \\
\text { - Be very descriptive of the behavior you want a child to demonstrate } \\
\text { - Tag teach: use a tag team approach with another teacher to address } \\
\text { power struggles } \\
\text { - Modify the warning if it is a negative trigger for the child } \\
\text { - Provide specific directions } \\
\text { - Allow the child to make a choice during the transition song (e.g., } \\
\text { "What color should we say in the song?" }\end{array}$ \\
\hline $\begin{array}{c}\text { Warning Prior to } \\
\text { Transition }\end{array}$ & $\begin{array}{l}\bullet \quad \text { Say "Five more minutes until __ } \\
\text { • Say "When you finish the } \_ \text {it will be time for ___." }\end{array}$ & $\begin{array}{l}\text { - Give direct one to one warning to child } \\
\text { - Modify warning time prior to transition compared to peers } \\
\text { - Give child responsibility to prepare other students for transition } \\
\text { (e.g., put the 'closed' sign on dramatic play area) } \\
\text { - Make a positive statement directly to the child about the next activity } \\
\text { - Use a visual timer (e.g., sand timer, bell timer) } \\
\text { - Tape a mark on the clock denoting transition time } \\
\text { - Use a transition song } \\
\text { - Use video/picture modeling }\end{array}$ \\
\hline Pre-teaching & $\begin{array}{l}\text { - Use print for explicit guidelines } \\
\text { - Use class-wide or small group modeling and statement of } \\
\text { expectations }\end{array}$ & $\begin{array}{l}\text { - Model and scaffold prior to target activities } \\
\text { - Create selective groupings or intentional groupings of children } \\
\text { - Use small group modeling with child included } \\
\text { - Use individual modeling with child before target activity } \\
\text { - Shorten language (reduce words) used for child } \\
\text { - Script intentional language to be used (e.g., all teachers and family } \\
\text { - Scmbers use the same scripted message) } \\
\text { - keep "heart" of message) } \\
\text { - Use picture schedules, picture prompts, video modeling } \\
\text { - Evaluate space to determine if it is supportive to desired behavior } \\
\text { - Use concerned care and consistent phrases (e.g., "I am worried that...." } \\
\text { - Practice prior to transition }\end{array}$ \\
\hline
\end{tabular}




\begin{tabular}{|c|c|c|}
\hline $\begin{array}{l}\text { Specific Verbal } \\
\text { Encouragement }\end{array}$ & $\begin{array}{l}\text { Use authentic and specifically targeted encouragement statements } \\
\text { that emphasize what the child did such as: } \\
\text { - "You wrote your name all by yourself" } \\
\text { - "I see you used red and blue and made purple." } \\
\text { - "Last week you couldn't climb across the bars and now you } \\
\text { can." } \\
\text { - "You helped rebuild her block structure and now she feels } \\
\text { better." } \\
\text { - "You told me how you feel and now I can help you solve the } \\
\text { problem." }\end{array}$ & $\begin{array}{l}\text { - Remind the child of previous success in similar situations } \\
\text { - Provide specific verbal encouragement for a task or behavior being } \\
\text { worked on by a child } \\
\text { - Actively watch for opportunities to encourage positive behavior } \\
\text { - Be consistent as a team in providing verbal encouragement (may use } \\
\text { - scripts) } \\
\text { - List the positive choices the child made throughout the day }\end{array}$ \\
\hline $\begin{array}{l}\text { Ratio of Positive } \\
\text { Statements versus } \\
\text { Redirections or } \\
\text { Planned Ignoring }\end{array}$ & $\begin{array}{l}\text { Use positive and encouraging statements that emphasize what the } \\
\text { child is doing such as: } \\
\text { - "You are sitting on your mat and you are ready for group." } \\
\text { - "When you heard the cleanup song, you picked up your blocks } \\
\text { right away." } \\
\text { - "You are learning so many new things." } \\
\text { - "You are growing and getting stronger." } \\
\text { - "You found a solution to your problem." }\end{array}$ & $\begin{array}{l}\text { - Make plans for specific behaviors to look for and on which you can } \\
\text { positively respond } \\
\text { - Make plans for specific behaviors to ignore as well as which } \\
\text { behaviors should be emerging in their place } \\
\text { - Actively look for opportunities to use positive statements } \\
\text { - Keep a self-tally of times positive statements are used }\end{array}$ \\
\hline $\begin{array}{c}\text { Acknowledgement } \\
\text { System }\end{array}$ & $\begin{array}{l}\text { - Use acknowledgement versus praise } \\
\text { - Be specific to the child's behavior } \\
\text { - Be mindful of 'less is best' and keep the language simple }\end{array}$ & $\begin{array}{l}\text { - Use specific scripts for all teachers to say the same thing about } \\
\text { targeted behaviors } \\
\text { - Use a teacher-designed reminder system when needed } \\
\text { - Acknowledge student task completion }\end{array}$ \\
\hline
\end{tabular}




\section{Discussion}

Empathetic, instructional, and caring contacts with children are necessary for helping children develop prosocial and desirable classroom behaviors (e.g, "You helped rebuild her block structure and now she feels better") and internalize attributions to their own efforts (e.g. "When you heard the cleanup song, you picked up your blocks right away"). Teacher responses to children's behaviors and proactive approaches to guidance need to be contemplated and intentional, but it is not necessarily using a range of tangible or social reinforcers often advocated for in behaviorist literature, especially within Tier I interventions. Consistent with the development of executive functions, teachers grounded their responses within a developmentalist view that children learn to regulate their thoughts and behavior over time. Instruction and practice are key strategies for enhancing working memory, inhibiting responding to inappropriate situations, and cognitive flexibility (Bjorklund \& Causey, 2018). As constructivists in the Arlitt Child Development Center's high performing classrooms, the rejection of stickers and praise in favor of teaching and scaffolding self-control and problem solving is a pedagogical norm. Within these constructivist classrooms, the experience of competence and being able to control aspects of his or her environment is a child's right that teachers facilitate and scaffold.

\section{Conclusion}

Intentional universal designs for learning, modification of the environment as needed, and the use of scripts to address challenging behaviors, when warranted by individual need or the classroom ecology, demonstrate one way to implement blended practice in early childhood education. The manner in which the Arlitt Child Development Center teachers addressed the Tier I Child Support Framework is an eco-constructivist model of blended practice that values child agency and is respectful of children's abilities to self-regulate their own behaviors. This is appropriate for the cultural context within most early childhood programs in the USA. Clearly then, within the scope of Tier I PBIS, a goal is to determine if a more comprehensive and intensive intervention is needed for persistent and at-risk behaviors. In Tier II interventions that require more structure and intensity with regard to one to one child interactions, the impact of exhibited challenging behaviors on the classroom ecology may manifest the need for extra supports that are more behavioral in approach. This will ensure that all children within the classroom enjoy a positive learning environment. However, within Tier I, perhaps PBIS should read Positive Behavioral and Instructional Supports as this would better reflect an ecoconstructivist's point of view. 


\section{Acknowledgements}

We wish to express our thanks and high regard to the dedicated and thoughtful teachers at the Arlitt Child Development Center and Dr. Dacia McCoy, who attentively worked with the teachers while obtaining her doctoral degree in school psychology.

\section{References}

Barnett, D.W., Bell, S.H., \& Carey, K.T. (1999). Designing preschool interventions: A practitioner's guide. New York, NY: The Guilford Press.

Bell, S.H., Carr, V.W., Denno, D.M., Johnson, L.J., \& Phillips, L. (2004). Challenging behaviors in early childhood settings: Creating a place for all children. Baltimore, MD: Paul H. Brookes.

Benedict, E.A., Horner, R.H., \& Squires, J.K. (2007). Assessment and implementation of positive behavior support in preschool. Topics in Early Childhood Special Education, 27(3), 174-192.

Blair, C. (2009). Self-regulation and school readiness. The International Child and Youth Care Network. Retrieved from https://bit.ly/2GD7I0B.

Bjorklund, D.F., \& Causey, K.B. (2018). Children's thinking: Cognitive development and individual differences, 6th Ed. Thousand Oaks, CA: Sage Publications.

Boat, M., \& Carr, V. (2007). Instructional and caring contacts in the inclusive early childhood classroom. Paper presented at the meeting of the Council for Exceptional Children (Louisville, KY, April, 2007).

Boat, M.B., Carr, V., Barnett, D., Macmann, G., Moomaw, S., Pan, W., \& Nichols, A. (2009). Instructional change in preschool classrooms: A study of empiricallybased teacher support. NHSA Dialog, 12(4), 303-326.

Bodrova, E., \& Leong, D. (2007). Tools of the mind: The Vygotskian approach to early childhood education, $2^{\text {nd }}$ ed. Upper Saddle River, NJ: Pearson Education, Inc.

Bronson, M.B. (2000). Self-regulation in early childhood. New York: The Guildford Press.

Bruner, J. (1966). Toward a theory of instruction. Cambridge, MA: Harvard University Press.

Carr, V., \& Boat, M. (2007). Eco-constructivism: A model for developmentally and individually appropriate classroom practice. Paper presented at the meeting of the Association for Childhood Education International Conference (Tampa, FL., May, 2007).

CAST, (n.d.) About universal design for learning. Retrieved from https://bit.ly/2E 10SMS.

Copple, C., \& Bredekamp, S. (eds.) (2009). Developmentally appropriate practice in early childhood programs serving children from birth through age $8,3^{\text {rd }}$ ed. Washington, DC: NAEYC.

Dewey, J. (1910). How we think. Boston, MA: D.C.Heath \& Co.

Dinnebeil, L., Boat, M., \& Bae, Y. (2013). Integrating principles of universal design into early childhood curriculum. Dimensions in Early Childhood, 41(1), 3-13.

Division for Early Childhood of the Council for Exceptional Children (DEC), National Association for the Education of Young Children (NAEYC), \& National Head Start Association (NHSA) (2013). Frameworks for Response to Intervention in 
Early Childhood: Description and Implications. Position Statement. Retrieved from https://bit.ly/2vJgTXM.

Division for Early Childhood (DEC). (2014). DEC recommended practices in early intervention/early childhood special education 2014. Retrieved from https://bit. ly/1fNQvz2.

Donovan, L., McCoy, D., Denune, H., Barnett, D., Graden, J., \& Carr, V. (2015). Preparing doctoral-level consultants for systems change: Implementing and supervising multi-tiered practices in early childhood education. Journal of Educational and Psychological Consultation, 25, 2-3, 252-275. doi:10.1080/104 74412.2014.929957.

Fox, L., Dunlap, G., \& Powell, D. (2002). Young children with challenging behavior: Issues and considerations for behavior support. Journal of Positive Behavior Interventions, 4(4), 208-217.

Gilliam, W. (2004). Pre kindergarteners left behind: Expulsion rates in state prekindergarten systems. Retrieved https://bit.ly/2IVxmf3.

Grisham-Brown, J., Hemmeter, M.L., \& Pretti-Frontczak, K. (2005). Blended Practices for Teaching Young Children in Inclusive Settings. Baltimore, MD: Paul H. Brookes.

Jolstead, K.A., Caldrella, P., Hansen, B., Korth, B.B., Williams, L., \& Kamps, D. (2016). Implementing positive behavior support in preschools: An exploratory study of CW-FIT Tier 1. Journal of Positive Behavioral Interventions. Retrieved from https://bit.ly/2pO9iSD. doi: 10.1177/1098300716653226.

Kohn, A. (1999). Punished by rewards: The trouble with gold stars, incentive plans, A's, praise, and other bribes. Boston, MA: Houghton Mifflin.

Lincoln, YS., \& Guba, EG. (1985). Naturalistic Inquiry. Thousand Oaks, CA: Sage Publications.

O'Leary, Z. (2005). Researching real-world problems - a guide to methods of inquiry. London, UK: Sage Publications.

Meyer, A., Rose, D., \& Gordon, D. (2014). Universal design for learning: Theory and practice. Wakefield, MA: CAST.

Piaget, J., \& Inhelder, B. (1962). The Psychology of the Child. New York, NY: Basic Books.

Rescorla, L., Achenbach, T., Ivanova, M., Harder, V., Otten, L., Bilenberg, N., \& Verhulst, F. (2011). International comparisons of behavioral and emotional problems in preschool children: Parents' reports from 24 cities. Journal of Clinical Child and Adolescent Psychology, 40, 456-467.

RTI Action Network, (n.d.). What is RTI? Retrieved from https://bit.ly/1R0hsNV.

Stringer, E.T. (2014). Action research. Thousand Oaks, CA: Sage Publications.

Sugai, G., Horner, R., Dunlap, G., Hieneman, M., Lewis, T., Nelson, C., Scott, T., Liaupsin, C., Sailor, W., Turnbull, A., Turnbull, H., III, Wickham, D., Reuf, M., \& Wilcox, B. (2000). Applying positive behavioral support and functional behavioral assessment in schools. Journal of Positive Behavioral Interventions, 2 , 131-143.

Skinner, B. F. (1953). Science and human behavior. New York, NY: Simon \& Schuster.

Vygotsky, L. (1978). Mind in society: The development of higher psychological processes. Cambridge, MA: Harvard University Press. 
